REVISTA DE DERECHO UNED, núm. 2, 2007

\title{
NOTAS EN TORNO A LA PRUEBA DEL DAÑO MORAL: UN INTENTO DE SISTEMATIZACIÓN *
}

\author{
Hugo A. CÁRdenas VillarReal \\ Profesor de Responsabilidad Civil \\ Universidad Andrés Belló \\ Paulina V. González Vergara \\ Profesora de Argumentación Jurídica \\ Universidad Católica del Norte (Sede Coquimbo)
}

Resumen: En este artículo se postula la necesidad de prueba del daño moral, como una exigencia ineludible de principios procesales y sustantivos fundamentales. Se desarrollan los aspectos principales de los que se cree ha de ser una teoría funcional de la prueba del daño moral.

Palabras clave: Responsabilidad, Daños morales, Prueba.

Abstract: In this article the need of proving the non-economic damage is propound as an unavoidable demand of both, procedural and fundamental principles. It develops the main aspects of what is believed it should be a functional theory of the non-economic damage proof.

Key words: Responsability, Non economic loss, Proof, Evidence

* El presente trabajo corresponde a la versión ampliada de la ponencia presentada por los autores en las IV Jornadas Nacionales de Derecho Civil (Olmué, Chile, 2006). 
Sin desmerecer el hecho de que la literatura jurídica nacional empieza a ser extensa en relación al problema del daño moral, en lo que atañe específicamente a su prueba, los estudios son escasos y por lo general, carentes del tratamiento sistemático que el problema amerita $^{1}$. Por ello, y atendiendo a que el problema de la prueba del daño moral ha sido identificado por autorizada doctrina como uno de los extremos pendientes de la teoría general de la responsabilidad civil $^{2}$, hemos encontrado oportuno intentar una primera aproximación al que sin duda, es uno de los tópicos más complejos y difíciles que dicha teoría presenta en la actualidad.

La dificultad de la prueba del daño moral viene dada principalmente por el hecho de que el mismo afecta a bienes jurídicos extrapatrimoniales, y porque es casi imposible hacer una valoración económica de dicho daño, cuando en ella no intervengan módulos de valoración objetivos, fijos y aisladamente considerados. En el desarrollo de este trabajo, por evidentes razones de espacio, nos centraremos en la primera de esas dificultades, abordando, las dos posiciones que tradicionalmente se han sostenido respecto de la prueba del daño moral (I); para luego, partiendo de la tesis afirmativa, analizar los que creemos son los principales aspectos de una teoría general de la prueba del daño moral (II). Se analizarán en esta segunda parte, los principios que fundamentan la exigencia de la prueba del daño moral (A), y los que consideramos deben ser los presupuestos de la prueba del mismo (B). Por último, se expondrán a modo de conclusiones algunas de las reflexiones y comentarios que el trabajo nos haya provocado (III).

1 Si bien la gran mayoría de las obras nacionales que tratan la responsabilidad civil, se refieren a la prueba del daño, y dentro de éste a la prueba del daño moral, más allá de unos pocos comentarios de sentencias, no existen estudios específicos sobre esta materia. Aunque en el derecho comparado a grandes rasgos se repite el panorama, en la doctrina argentina pueden verse, MOSSET ITURRASPE, Jorge y NOVELLINo, Norberto, La prueba en el proceso de daños, En: AA. VV., Derecho de Daños, tercera parte. Buenos Aires: Ed. La Rocca, 2000.; Agoglia, María, Boragina, Carlos y MEZA, Jorge. La prueba del daño. En Revista de Derecho de Daños. N. ${ }^{\circ}$. Mendoza: Rubinzal-Culzoni, 1999. pp. 157-172; Arazi, Roland. Prueba del daño moral. En: Revista de Derecho de Daños. N. ${ }^{\circ}$ 6. Mendoza: Rubinzal-Culzoni, de 1999. pp. 103-111; IRIBARNE, Héctor. La prueba en el juicio de daños a la persona. En: Revista de Derecho de Daños. N. ${ }^{\circ}$ 4. Mendoza: Rubinzal-Culzoni, 1999. pp. 63-100.

2 Fueyo LANerI, Fernando. Instituciones de Derecho Civil Moderno. La resarcibilidad del daño moral como tutela de los bienes y derechos de la personalidad. Santiago: Ed. Jurídica de Chile, 1990. pp. 53 y ss.; Domínguez Hidalgo, Carmen. El daño moral t. 1 y 2. Santiago: Ed. Jurídica de Chile, 2002. pp. 682 y ss.; CorRal Talciani, Hernán. Lecciones de responsabilidad civil extracontractual. Santiago: Ed. Jurídica de Chile, 2004. pp. 163 y ss. 
Adviértase, que metodológicamente, el desarrollo de la exposición se encuentra centrado en el análisis de un grupo de sentencias que consideramos paradigmáticas para el estudio del tema; y aunque pueda objetarse a dicho método, la falta de uniformidad tristemente característica de nuestra jurisprudencia, creemos imprescindible su uso, pues solo desde esta perspectiva de análisis podremos cotejar los aciertos y desaciertos de nuestra magistratura y - a través de la discusión y el diálogo-, contribuir de alguna manera a la consolidación de las más justas y correctas doctrinas jurisprudenciales.

\section{LA EXIGENCIA PROBATORIA: ¿DEBE PROBARSE EL DAÑO MORAL?}

Tradicionalmente han sido dos las posturas que ha mantenido la jurisprudencia nacional en lo que a prueba del daño moral se refiere. Así, por un lado, nos encontramos con la más antigua en el tiempo y - ya un poco trasnochada doctrina-, de que el daño moral no requiere de prueba; por otro, con la moderna tesis que defiende que el daño moral, al igual que cualquier otro tipo de daño, debe ser probado por quien pretenda su reparación. Veremos seguidamente, como ambas posturas antagónicas conviven en las doctrinas de nuestros tribunales de justicia, sin que de momento podamos hablar de un firme y constante pronunciamiento a favor de una de ellas.

\section{A. LA TESIS NEGATIVA: EL DAÑO MORAL NO REQUIERE DE PRUEBA}

Tanto la doctrina como la jurisprudencia más clásica de nuestro país han sostenido que el daño moral, a diferencia de lo que sucede con el daño material, no necesita de ninguna clase de prueba ${ }^{3}$. En el tiempo, esta tesis clásica ha encontrado dos vías diferentes de desarrollo jurisprudencial que, con alguna variación en su enunciado, han conducido a la misma solución práctica:

${ }^{3}$ Un amplio seguimiento a través de la jurisprudencia de esta vía puede verse en, DIEz SCHWERTER, José Luis. El daño extracontractual. Jurisprudencia y doctrina. Santiago: Ed. Jurídica de Chile, 2002. pp. 133 y ss..; y en VICARI, Alejandro y UGARTE, Eduardo, Edición del curso de responsabilidad civil extracontractual del profesor Enrique Barros Burie, Santiago, 1999, Tesis de Licenciatura (Licenciado en Ciencias Jurídicas y Sociales). Universidad de Chile. Facultad de Derecho. Departamento de Derecho Privado, pp. 117 y ss. 
La primera de las referidas vías, fundamenta la falta de exigencia probatoria en la especial naturaleza, es decir, en el carácter espiritual y subjetivo del daño extrapatrimonial; lo que haría no sólo innecesario, sino imposible la acreditación de su existencia ${ }^{4}$. En palabras de nuestras Cortes, "El daño moral es de indole netamente subjetiva y su fundamento se centra en la propia naturaleza afectiva del ser humano, de manera que puede decirse que tal daño se produce siempre en un hecho externo que afecta la integridad moral del individuo y por lo tanto la apreciación de éste debe considerarse entregada al juez, pues dada su indole es inconcuso que no puede ni requiere ser acreditado" ${ }^{5}$.

Como puede verse, la jurisprudencia partiendo y tomando como base de su argumentación un concepto «primitivo» de daño moral (lo identifica con el dolor subjetivo), llega a la conclusión de que se trataría de una materia entregada completamente al arbitrio de los jueces del fondo. Estos, determinarían su existencia y monto de manera discrecional, sin necesidad de fundamentar sus decisiones en la materia, y sin que exista la posibilidad de que tales decisiones sean revisadas por los tribunales superiores.

Más recientemente, una segunda vía jurisprudencial, que en principio exigiría la prueba del daño moral, llevará en la práctica a la misma solución que la anterior ${ }^{6}$. Se afirmará así, que si el daño moral puede ser definido como la violación de un derecho extrapatrimonial, la mera prueba de la transgresión del derecho, conllevaría la prueba de la existencia del daño. En palabras de la Corte, se entenderá el daño moral «... como la lesión o agravio, efectuado culpable o dolosamente, de un derecho subjetivo de carácter inmaterial o inherente a la persona humana y que es imputable a otro hombre. Se sigue de este concepto, como consecuencia necesaria, que la demostración de la trasgresión o agravio del derecho subjetivo importa, al mismo tiempo, la prueba de la existencia del daño moral. Por consiguiente, en el concepto y naturaleza del daño, resultan indiferentes las repercusiones de orden psíquico que el agravio originaría en el individuo que lo sufre. Sea que se exprese en dolor, sufrimiento, aflicción, incomodidad $u$ otras penalidades» ${ }^{7}$ (el destacado es nuestro).

Nótese que puede hablarse de una nueva versión de la teoría clásica, pues si bien la utilización de un concepto más técnico de daño

\footnotetext{
4 Domínguez H., C., El daño ..., Op. Cit., p. 682.

${ }^{5} R D J$, T. LXXXI, secc. 2., 1984 p. 121

6 En este mismo sentido, Corral, H., Lecciones ..., Op. Cit., pp. 165-166.

7 RDJ, T. LXXXII, secc. 2. ${ }^{\mathrm{a}}$, 1985, p. 6.
} 
moral (lesión a los derechos extrapatrimoniales) nos ayuda a resolver ciertos casos límite en que la utilización del concepto primigenio (pretium doloris) nos arrojaría resultados injustos (piénsese en los casos del inconciente o el demente) ${ }^{8}$, ello no puede hacerse de cualquier manera; y mucho menos, desentendiéndose por completo de los efectos de esa transgresión ${ }^{9}$. Y es que, como dice Diez-PICAzo ${ }^{10}$, si bien la lesión de un derecho ajeno puede constituir un presupuesto de los deberes de indemnizar cuando el daño se ha producido, el daño, siendo algo distinto, no ha de quedar embebido en la sola lesión del derecho, puesto que su indemnización exige siempre como presupuesto su existencia.

Como corolario debe decirse, que en sus dos versiones, la tesis que niega la exigencia probatoria del daño moral a merecido la crítica de la doctrina especializada ya que, a pesar de que resulta innegable que la naturaleza del daño moral hace extremadamente compleja su acreditación, la exigencia de prueba arranca de principios sustanciales y procesales que sostienen y fundamentan el moderno Estado de Derecho. Nótese además, que eliminar la exigencia probatoria equivale a desplazar la atención de la reparación del perjuicio a la conducta dañosa; lo que en última instancia exalta la función punitiva que, al menos entre nosotros, se pretende excluida del sistema de responsabilidad civil ${ }^{11}$. Por último, y aunque resulte obvio, no está de más repetir, que la ausencia de exigencia probatoria es tierra fértil para el nacimiento de condenas arbitrarias (v.gr. por daños inexistentes o a montos no razonables), y potencia la disparidad de las decisiones judiciales: en fin, un golpe a la justicia y a la seguridad jurídica ${ }^{12}$.

8 Cfr. CÁRdenas Villarreal, Hugo. Daño moral: algunas notas para su delimitación, comentario de jurisprudencia. En Jurisprudencia al Día. Año 5, n. ${ }^{\circ} 285$, Santiago: Ed. Lexis Nexis, abril de 2006, pp. 42-45.

${ }^{9}$ Cuestión distinta sería afirmar, que tal transgresión, una vez probada, pudiera constituir un indicio a partir del cual el juez pueda legítimamente presumir la existencia del daño moral. Como se verá más adelante, las consecuencias de una u otra afirmación tienen importantes diferencias (Ver, II. B. 1).

10 Diez-Picazo, Luis. Derecho de daños. Madrid: Civitas, 199. p. 328.

11 Lo que decimos puede verse claramente en otros países, donde la función punitiva de la condena por daño moral es abiertamente reconocida. Un inmejorable ejemplo de lo que decimos lo constituye una sentencia Brasileña que en lo que nos interesa dice, «Os danos morais, que independem de prova, devem ser fixados em valor suficiente para inhibir nobas conductas lesivas...» (1. TACSP-4. $^{a}$ C.-Ap.618306-4Rel. Carlos Bittar-J.18.10.1995; Sentencia citada por SToco, Rui, Tratado de responsabilidade civil, 6. ${ }^{\text {a }}$ ed. Sao Pablo: Ed. Revista Dos Tribunais, 2004. p. 1697).

12 Domínguez H., C., Aspectos modernos de la reparación por daño moral. Contraste entre el derecho chileno y el derecho comparado, En: Revista de Derecho. Año 6. Coquimbo: Universidad Católica del Norte. 1999, pp. 36 y ss. 


\section{B. LA TESIS POSITIVA: EL DAÑO MORAL DEBE PROBARSE}

Desde hace algunos años, con innegable influencia de la doctrina, ha comenzado a tener mayor peso en nuestra jurisprudencia, una nueva línea interpretativa que defiende la necesidad de que los perjuicios morales deben ser efectivamente acreditados en el proceso judicial, por quien los invoca. Así, la Corte de Santiago ha mantenido, que en «...relación con la acción de resarcimiento por daño moral que ha intentado el ofendido por el delito, preciso es tener en cuenta que todo daño debe probarse, sea patrimonial o extrapatrimonial. En efecto sobre la prueba del daño moral rigen las reglas generales, por lo que se requiere que el actor pruebe la verdad de sus proposiciones, esto es, que sufrió un daño cierto o real, sin que pueda darse por establecido o priori el agravio, su entidad y magnitud y las consecuencias que de él se han derivado» ${ }^{13}$.

Como no puede ser de otra manera, entendemos que esta es la tesis a potenciar y la que debe cimentar en adelante cualquier intento de sistematización de la materia, pues como ya adelantamos más arriba y profundizaremos más abajo, la exigencia probatoria arranca de principios sustantivos y procesales que fundamentan el Estado de Derecho. Además, el hecho de que dicha doctrina sea todavía incipiente y coexista con la contraria, constituye la coyuntura en la cual cobra sentido concentrar los esfuerzos en desarrollar una teoría general de la prueba del daño moral. Dicha teoría, tomando como centro un concepto funcional de esta clase de perjuicios ${ }^{14}$, debe partir por

13 Corte de Apelaciones de Santiago, de fecha 30 de mayo de 2001, Rol N. ${ }^{\circ} 25.892-$ 2001, en La Semana Jurídica, (materia penal), semana del 13 al 19 de agosto de 2001 . En este mismo sentido, Corte de Apelaciones de Santiago, de fecha 24 de junio de 1997, GJ, n. ${ }^{\circ}$ 204, p.141; y más recientemente Corte de Apelaciones de Santiago, 6 de marzo de-2006, Rol. 3141-2003.

${ }^{14}$ Los conceptos funcionales son aquellos que son construidos desde la función que están llamados a cumplir dentro del sistema jurídico en el cual se insertan. Un concepto funcional de daño moral se sustenta en primer lugar en su carácter de garantía, en cuanto categoría orientada a la protección integral de la persona (tanto en sus aspectos patrimoniales como extrapatrimoniales). Desde esta perspectiva, un concepto de daño moral concebido únicamente como pretium doloris resulta insuficiente. Por cuanto por ejemplo, no protege a individuos cuya capacidad de comprensión intelectual no existe (víctima inconsciente o en estado de coma) los cuales no pueden experimentar sentimientos de dolor; como tampoco protege, a aquellos en que dicha capacidad no se encuentra madura o se presenta disminuida (menores o deficientes mentales), y que por lo mismo, pudieren hasta disfrutar del agravio. Lo anterior, sin desconocer su utilidad inicial respecto a la admisibilidad de esta clase de perjuicios y de aquella que mantiene en tanto se le considere como uno, de entre otros varios, tipos o clases de daño moral. Respecto a los conceptos funcionales, LARENZ, Kart. (2001). Metodología de la ciencia del derecho. (Marcelino Rodríguez Molinero, Trad.). Barcelona: Ariel Derecho. pp. 473 y ss. 
explicitar los principios que le sirven de sustento y, desde allí, desarrollar los distintos presupuestos que la componen, de cara a mejorar la justa reparación de este tipo de perjuicios.

\section{TEORÍA DE LA PRUEBA DEL DAÑO MORAL: UN INTENTO DE SISTEMATIZACIÓN}

Ciertamente resultaría temerario intentar aquí, darle cabal forma a una teoría de la prueba del daño moral, sin embargo, en adelante intentaremos un acercamiento a algunas de los principios y postulados que puedan servir para relacionar de mejor manera, los fenómenos que giran en torno a la prueba del daño extrapatrimonial. En este apartado veremos entonces de manera consecutiva, los principios que de forma general, fundamentan la exigencia de prueba del daño moral (A); y los presupuestos o requisitos que se deben cumplir para dar por acreditado el mismo en sus distintas categorías (B).

\section{A. PRINCIPIOS QUE FUNDAMENTAN LA EXIGENCIA DE PRUEBA DEL DAÑO MORAL}

\section{El principio del debido proceso ${ }^{15}$ : el derecho a una sentencia motivada y el derecho a defensa}

La garantía del debido proceso se encuentra consagrada en nuestra Carta Fundamental, como el derecho a un justo y racional procedimiento y conlleva el deber de la motivación de las decisiones de autoridad, especialmente, de las resoluciones judiciales. De esta forma, el juez debe exteriorizar en la sentencia las razones que justifican su decisión, no bastando su mera enumeración sino que debe expresar de manera clara y precisa los razonamientos - tanto de hecho como de derecho- que la fundamentan; de modo que sea posible la reconstrucción de tales razonamientos (exigencia constitucional que se encuentra recogida y concretada en los artículos $170 \mathrm{n} .{ }^{\circ} 4 .^{\circ}$ del CPC y el artículo 342 c. y d., del NCPP ).

15 Sobre este tema, GozAINI, Osvaldo Alfredo, El debido proceso en la actualidad; Hoyos, Arturo, El debido proceso en el sistema jurídico de Panamá; y, MorA MoRA, Luis Paulino, Las garantías del procesado como parte del debido proceso, todos En I Congreso Panameño de Derecho Procesal. Ciudad de Panamá, agosto de 2004. pp. 351-366, 307-328 y 329-349, respectivamente. 
Como garantía contra la arbitrariedad judicial, la motivación de las sentencias no sólo debe ser entendida desde una perspectiva formal (explicitación de los motivos o razones que han determinado la respectiva decisión), sino fundamentalmente, desde un punto de vista material (corrección de las razones aducidas). Para el tema que nos ocupa, ello no sólo implica que deben ser correctas las conclusiones jurídicas a las cuales se arribe, sino que las mismas deben estar precedidas por una correcta determinación de los hechos, realizada a partir de los antecedentes que conforman el proceso.

En términos generales, el juez debe atenerse al fundamentar la sentencia a los hechos alegados por las partes y respecto de los cuales se haya rendido prueba ${ }^{16}$. A este respecto nuestros tribunales han señalado que, "En las sentencias judiciales generalmente olvidan fundar la reparación de daño moral o extrapatrimonial, limitándose lisa y llanamente a expresar una cifra por ese concepto, como lo hace precisamente la sentencia recurrida en estos autos. Tal vez se cree que la discrecionalidad en la fijación del monto respectivo, y la aplicación de un concepto indeterminado como es la equidad, permitirían eximirse del deber de convicción que pesa sobre todo juzgador, en cualquier materia que sea, y que, por lo demás, está reiterado en los $n .^{\circ} s 5 .^{\circ}$ y $6 .^{\circ}$ del artículo 500 del Código de Procedimiento Penal» ${ }^{17}$.

Además debe tenerse en cuenta, que el derecho al debido proceso también contempla el derecho a defensa, derecho que en materia probatoria implica, a su vez, la posibilidad de presentar pruebas de descargo. En consecuencia, el derecho al debido proceso, en sus dos acepciones aludidas (en tanto derecho a una sentencia motivada y derecho a defensa), exige necesariamente la rendición de prueba sobre cualquiera de los extremos que se pretenda reparar: la prueba del daño moral se constituye así en una garantía en contra de la arbitrariedad judicial.

\section{Principio de la reparación integral del daño: la zona límite entre la función reparadora y la pretendida función punitiva de la responsabilidad civil.}

Si bien este principio se entiende orientado a permitir la reparación de toda clase de perjuicios, la afirmación del mismo no debe lle-

${ }^{16}$ En general, salvo aquellos casos excepcionales de iniciativa probatoria del juez, y respecto de hechos que no requieren prueba (v.gr. hechos notorios y reconocidos por la parte contraria).

17 GT, T. 46, p. 93. 
var — como pretende alguna jurisprudencia-, a relajar la exigencia probatoria pues, del mismo deviene también como condición necesaria, que aquello que se pretende reparar resulte probado ${ }^{18}$. Otra cosa supondría utilizar la institución punitivamente, y aunque no resulta pacífico sostener que la responsabilidad civil tiene únicamente una función reparadora, el daño sigue constituyendo un presupuesto indispensable de la obligación de indemnizar perjuicios ${ }^{19}$.

Por lo dicho, si hablamos de responsabilidad civil, y por ende, de la obligación de indemnizar el menoscabo sufrido, aún cuando pudiera considerarse lícito asignarle una función punitiva a la responsabilidad civil, dicha función deberá ser necesariamente accesoria, y en ningún caso desprendida de la existencia del perjuicio. Sobre el carácter fundamental del daño nuestra jurisprudencia ha señalado que "... la ley atiende al individuo que sufre cuando es lesionado en sus intereses materiales y morales; del conjunto de preceptos que rigen las indemnizaciones provenientes del daño, se desprende que su procedencia supone la existencia de un perjuicio, menoscabo, disminución, o pérdida para quien lo experimenta o sufre, y la obligación de indemnizarlo para el que lo produce como consecuencia de un delito o cuasidelito" (el destacado es nuestro) ${ }^{20}$.

En esta línea de principio, ya sea para justificar la concesión de un monto menor al solicitado o derechamente, para rebajar condenas impuestas por tribunales inferiores, algunos fallos han comenzado a aplicar explícitamente el enriquecimiento sin causa como límite para la fijación del monto de la indemnización por daño moral ${ }^{21}$. Así se dicho, que «El monto del daño de la indemnización de perjuicios debe regularse prudencialmente, cuidando que la suma fijada se limite a compensar el daño sin llegar a constituir un enriquecimiento sin causa» ${ }^{22}$.

18 En este mismo sentido, Arazi, R., Prueba ..., Op. Cit., p. 103, quien señala al respecto que «La naturaleza resarcitoria nos coloca frente al problema de la prueba del daño».

19 Sobre el rol jurídico del daño, Diez S., J. L., El daño ..., Op. Cit., p. 25 y ss. AGoglia, M., Boragina, C. y Meza, J., Op. Cit., La prueba ..., p. 164.

${ }^{20} R D J$, T. LXV, secc. $4 .^{\circ}, 1968$, p. 323.

21 Como veremos más adelante al tratar los presupuestos, creemos que el monto solicitado por la parte demandante constituye un límite objetivo a la indemnización que puede ser concedida, y en consecuencia, si bien puede ser admitida una rebaja del monto demandado, en ningún caso, podrá el tribunal conceder una suma superior so pena de incurrir en el vicio de ultra petita. Y por ende, abrir la posibilidad de que la sentencia sea anulada en casación.

${ }^{22} R D J$, T. LXXIX, secc. 4. ${ }^{\circ}, 1982$, p. 123. Sentencia en la cual la Corte de Apelaciones de Santiago rebaja la indemnización concedida por daño moral por el tribunal de primera instancia, en una causa por el delito de lesiones. 
Como puede desprenderse de lo señalado, la acreditación del daño se constituye en requisito o condición principal para la procedencia de la correspondiente acción de daños y perjuicios: así como no hay responsabilidad sin daño, no hay acción sin interés. Lo dicho fue además corroborado por la Corte Suprema cuando entendió, "Que, al no estar acreditado los periuicios reclamados ni la necesaria relación causal entre el acto que se impugnó y el presunto daño reclamado, no ha nacido para el actor el derecho a ser resarcido ni la obligación de la demandada de responder por la actuación imputada ${ }^{23}$.

En síntesis, la exaltación del principio de reparación integral en relación con la función reparadora que se le reconoce a la responsabilidad civil, no solo no puede servir para relajar la exigencia probatoria; sino que muy por el contrario, se constituye en fundamento ineludible de la exigencia de prueba del daño moral.

\section{B. PRESUPUESTOS DE LA PRUEBA DEL DAÑO MORAL.}

Al momento de pensar en los presupuestos o elementos fundamentales de una teoría de la prueba del daño moral debemos buscar las respuestas a las siguientes preguntas: ¿Qué se debe probar? ¿quién debe probar? y ¿cómo debe probar?. Desde el punto de vista procesal, la primera de estas preguntas nos introduce al tema del concepto del daño moral; la segunda, nos introduce en el tema de la carga de la prueba; y la tercera, aunque muy ligada con la primera, nos lleva al problema de la idoneidad de las pruebas. Veámoslos uno por uno.

${ }^{23}$ Sentencia de Corte Suprema de fecha 09 de noviembre de 2004. Rol n. ${ }^{\circ} 228-03$.

En este mismo sentido, "Que en el caso sub-lite, la actora no probó de forma fehaciente los hechos fundantes de la responsabilidad extracontractual que invoca en su demanda, ni el daño moral mismo, según lo razonado precedentemente» Sentencia de fecha 28 de julio de 2004, causa Rol n. ${ }^{\circ} 7249-99$. También debe tenerse presente que la falta de prueba del daño moral tiene un efecto expansivo respecto de otros requisitos de la responsabilidad civil, por cuanto difícilmente podrá establecerse relación de causalidad alguna respecto de un daño que no ha sido acreditado. Así, se ha fallado que "tampoco se ha probado en autos la concurrencia de daño moral, no siendo suficiente, a juicio del tribunal, su mera invocación, pues, incluso en su determinación, deben existir elementos objetivos que permitan relacionar el «sufrimiento» de quien lo alega, con los hechos que lo motivan, a fin de establecer la relación de causalidad correspondiente, elementos que, como se observa, no han sido debidamente acreditados» Sentencia del Tribunal de Letras de Arica, de fecha 03 de julio de 2001. Rol N. ${ }^{\circ} 23.809-00$. 


\section{El problema del concepto del daño moral: ¿Qué debe probarse cuando se alega daño moral?}

Evidentemente, cuando nos disponemos a desentrañar los aspectos probatorios del daño moral, nuestra atención se dirige en primer lugar al concepto, pues, solamente una vez delimitado éste, vislumbraremos a qué hechos debemos dirigir la prueba y cuáles son, de entre los medios permitidos, los más idóneos para conseguir nuestro objetivo. En nuestro ámbito, a pesar de que el concepto primogénito de daño moral sigue muy arraigado, la doctrina y la jurisprudencia empiezan a dar cabida a un concepto amplio de daño moral, donde además del tradicional pretium doloris, encuentran acomodo otras categorías como la lesión a derechos o bienes de la personalidad, u otras más modernos, como el perjuicio estético o la pérdida de la chance ${ }^{24}$.

La utilización de un concepto amplio de daño moral, a efectos probatorios, lleva aparejada la necesidad de que el mismo sea subdividido en distintas categorías. Y es que, haciendo categorías o subtipos, no solo podremos abstraer con precisión aquello que se está reparando, sino que nos será más fácil identificar quiénes tienen la legitimación activa para reclamar y, por tanto, quienes deben acreditar la existencia del daño. El desarrollo del principio de reparación integral del daño, conlleva pues la exigencia metodológica de hacer una tipología que oriente y determine la reparación del daño moral: ¡he aquí la primera y más importante tarea pendiente dentro de la teoría del daño moral!

\section{El problema de la carga de la prueba: ¿Quién debe probar el daño moral?}

En línea de principio, la prueba de la existencia del daño moral no difiere del sistema probatorio general. De esta manera, la prueba de la existencia y extensión de los perjuicios corresponde a quien los alega, es decir, a la víctima o acreedor (artículo 1698 del CC.), a menos que la propia ley establezca lo contrario ${ }^{25}$.

${ }^{24}$ Puede verse, con citas de doctrina y jurisprudencia nacional, CáRdenas V., Hugo y González Vergara, Paulina. Notas sobre el daño moral: concepto, prueba y avaluación en una reciente sentencia de la Corte de Apelaciones de Santiago, nota a fallo. En Revista de Derecho. Año 12, n. ${ }^{\circ} 2$. Coquimbo: Universidad Católica del Norte, julio-diciembre de 2005. pp. 181-189.

${ }^{25}$ Lo cual en nuestro sistema sólo se produce en materia de responsabilidad contractual en el caso de los intereses de obligaciones dinerarias (artículo 1545 del CC.) y de la cláusula penal (artículo 1535 del CC.). 
Ahora bien, no debe pasarse por alto, que a pesar de que no existen en nuestro derecho presunciones legales de este tipo de perjui$\mathrm{cio}^{26}$, partiendo del análisis de nuestra jurisprudencia se puede establecer que a efectos de distribución de la carga de la prueba, se puede hablar de dos "tipos" de daños morales: por un lado, aquellos cuya existencia puede presumirse; y por otro, aquellos cuya existencia debe ser acreditada mediante pruebas distintas a la de presunciones o no sólo por éstas. Es lo que se desprende de algunos fallos como el emitido por el Tribunal de Letras de Antofagasta cuando sostuvo que, "Por último, no está de más hacer presente, en cuanto a la prueba del daño moral que a pesar de que tanto la doctrina como la jurisprudencia mayoritaria coinciden en señalar que el daño moral no requiere prueba, que sólo basta que la víctima acredite la lesión de un bien personal para que se infiera el daño; en este caso, que se trata de daños a una cosa corporal, no se puede presumir de ello el daño moral, entendido como "el dolor, pesar o molestia que sufre una persona en su sensibilidad física, en sus sentimientos o afectos o en su calidad de vida». Cierto es que otro tipo de lesiones a la integridad física o síquica permiten inferir el daño moral, pero en el caso de autos debió ser acreditado en cuanto a su existencia... ${ }^{27}$.

En general, la doctrina no cuestiona la utilización de este medio de prueba respecto de la acreditación del daño moral ${ }^{28}$, lo que nos pa-

${ }^{26}$ Una presunción legal de daño moral puede verse, por poner un ejemplo, en los artículos 1084 y 1085 del CC. Argentino cuando dice:

Artículo 1084.

Si el delito fuere de homicidio, el delincuente tiene la obligación de pagar todos los gastos hechos en la asistencia del muerto y en su funeral; además lo que fuere necesario para la subsistencia de la viuda e hijos del muerto, quedando a la prudencia de los jueces, fijar el monto de la indemnización y el modo de satisfacerla.

Artículo 1085.

El derecho de exigir la indemnización de la primera parte del artículo anterior, compete a cualquiera que hubiere hecho los gastos de que allí se trata. La indemnización de la segunda parte del artículo, sólo podrá ser exigida por el cónyuge sobreviviente, y por los herederos necesarios del muerto, si no fueren culpados del delito como autores o cómplices, o si no lo impidieron pudiendo hacerlo.

${ }^{27}$ Sentencia del Tribunal de Letras de Antofagasta, de fecha 31 de julio de 2002, Rol N. ${ }^{\circ} 39.010-01$.

${ }_{28}$ Sobre la admisibilidad y requisitos de la prueba de presunciones en esta materia, por todos, CORRAL T., H., Lecciones ..., Op. Cit, p. 167. FueYo LANERI, F., Instituciones ..., Op. Cit., p. 107. Sobretodo, se recalca el que las presunciones deben fundarse sobre hechos probados. Cuestión fundamental, pues de lo contrario se trataría no de una presunción sino de una mera ficción. Figura que sólo es admisible cuando es dispuesta en casos excepcionalísimos por el legislador, y aún en ellos, su legitimidad es ampliamente discutida. Sobre esta materia, LuNA SERrano, Agustín, Las ficciones legales y algunas figuras afines. En Caminos Romanos (Viae Romanae), Estu- 
rece acertado ya que su uso es perfectamente lícito siempre y cuando se cumplan con los respectivos requisitos legales, las circunstancias que sirven de base a la presunción de los daños estén debidamente acreditadas en el proceso, y en todo caso, se admita la prueba en contrario $^{29}$.

dios en homenaje a Francisco Samper Polo, Juan David Terrazas ed., Santiago: Universidad Andrés Bello, 2006. pp. 215-223. Trabajo en el cual se afirma acertadamente que la presunción iuris et de iure es completamente equiparable en sus efectos a la ficción legal. De allí nuestro rechazo a la práctica habitual en esta materia por parte de los jueces de construir presunciones judiciales sin admitir la presentación de pruebas de descargo: de esa manera el magistrado invade un ámbito en el que en principio solo podría tener injerencia el legislador.

${ }^{29}$ En esta materia, creemos que es útil llamar la atención sobre dos aspectos desarrollados por el derecho comparado latinoamericano, el del principio de las cargas probatorias dinámicas y el de la diferenciación entre presunciones legales e indicios como base de las presunciones judiciales. Ambos, escasamente desarrollados en nuestro medio. En virtud del principio de las cargas probatorias dinámicas, «le incumbe la carga probatoria a quien por las circunstancias del caso y sin que interese que se desempeñe como actora o demandada se encuentre en mejores condiciones para producir la probanza respectiva", de modo que "corresponderán mayores cargas a quien dispone de mejores posibilidades en razón a la posesión de medios idóneos de prueba" (por ejemplo quien está uen mejores condiciones técnicas, profesionales o fácticas para producirlas»). Derecho Argentino, Sentencia de Juzgado Civil 74, Exp. n. ${ }^{\circ}$ 453/96, caratulado "Quantin Norberto Julio c/Benedetti Jorge Enrique». Buenos Aires, abril de 2006. Principio que en cooperación con el de reparación integral, podrían justificar la posibilidad de aplicación de presunciones judiciales en determinados casos. Como aquellos de responsabilidad médica, en los cuales claramente el paciente se encuentre en una situación más desfavorable para, por ejemplo, acreditar la anormalidad del daño.

En cuanto al segundo de tales aspectos, y luego de afirmar el principio según el cual, el juez no puede legítimamente eximir de prueba los hechos alegados por las partes, salvo que el legislador se lo imponga. La importancia de hacer la distinción entre las presunciones legales y los indicios que pueden servir de base a presunciones judiciales, radica en que las primeras deben aplicarse toda vez que aparezcan demostrados los hechos que les sirven de fundamento; por el contrario, en el caso de los indicios, una vez acreditados los hechos que los constituyen, "la presunción será construida por el juez, en cada caso concreto, según su libre criterio, siempre que existan los elementos necesarios para aplicar la respectiva regla de la experiencia y no obre en el proceso otra prueba que permita concluir que se trata de una situación especial, que se aparta de la generalidad». Derecho Venezolano, Sentencia n. ${ }^{\circ} 2812$ del 02/02/06. Ponente: Alier Hernández Enríquez. Actor: Blanca María Guevara Escobar y otros. Consejo de Estado, Sala de lo contencioso administrativo., sección tercera, resolución que también establece, que «... el juez no está autorizado para eximir de prueba los hechos alegados por las partes, como fundamento de sus pretensiones y defensas, salvo que el legislador se lo imponga. De alli la importancia de establecer claramente la diferencia entre las presunciones legales y aquéllas que elabora el juez con fundamento en hechos debidamente probados en el proceso, dando lugar a la construcción de indicios, medio probatorio regulado por nuestra legislación procesal civil. Por esta razón, la doctrina ha precisado que las presunciones no constituyen medios de prueba, dado que, al ser establecidas por el legislador, implican realmente que determinados hechos están exentos de demostración.". 
La prueba de presunciones constituye uno de los llamados resquicios solidaristas consagrados dentro del sistema probatorio ${ }^{30}, \mathrm{y}$ queda de manifiesto su importancia respecto de aquellas materias en que, como es el caso del daño moral, la prueba directa es extremadamente compleja ${ }^{31}$. Su utilización permite armonizar de mejor manera los principios que fundamentan la exigencia de prueba de esta clase de perjuicio con el principio de reparación integral.

La tarea pendiente a este respecto, es el desarrollo de la tipología de daños morales que pueden ser presumidos y aquellos que no, a partir de la determinación de ciertos grupos de casos que permitan la aplicación de estas dos categorías de daños de una manera más uniforme y transparente, y que reduzca además la arbitrariedad que su utilización no fundamentada podría ocasionar ${ }^{32}$. Sirvan como ejemplo de estos tipos, el caso del daño moral indirecto o por

30 Aquellos que en el contexto de un sistema en que se centra «la cuestión del onus probandi en el exclusivo interés de la parte litigante» ( $y$ en este sentido, un sistema individualista de Derecho Procesal) «permiten al juez-independientemente del interés particular de los contendores- propender a la operatividad concreta del valor justicia mediante la aplicación de mecanismos normativos complementadores de la regla general». Agoglia, M., Boragina, C. y MEZa, J., La prueba ..., Op. Cit., p. 163.

31 Se suele señalar que en la mayoría de los casos, el daño moral tendría la categoría de hecho normal, y en cuanto tal, no debe ser probado por quien lo alega. Tal calificación vendría dada por la aplicación de reglas o máximas de experiencia, en tanto éstas indican que la muerte de un familiar o ciertos tipos de lesiones producen en la generalidad de las personas sufrimientos o afectación de bienes extrapatimoniales constitutivos de daño moral. Los hechos normales al basarse en un «estándar jurídico, de nivel medio de conducta, de comportamiento, de reacciones» invertirían la carga de la prueba, correspondiendo a quien alega su no ocurrencia el probarla; en tanto, el hecho generador de dichos sufrimientos o afectación debe ser probado. ARAZI, R., Prueba ..., Op. Cit., pp. 106-108; IRIBARNE, H., La prueba ..., Op. Cit., pp. 76-77. Ciertamente en muchos casos de daño moral nos encontramos frente a un hecho normal, sin embargo, creemos que afirmar que en ellos el daño no debe ser probado no es la solución más conveniente. La calificación de hecho normal más que eximir de prueba a quien lo alega, autoriza al juez a aplicar la prueba de presunciones, y en este sentido, quien lo alega ha de probar siempre el hecho fundante y el juez ha de respetar los requisitos establecidos respecto de la procedencia de esta clase de prueba. Si de lo que se trata es disminuir la arbitrariedad, es altamente peligroso la utilización de la categoría de hecho normal como mecanismo que permite relevar a las partes sin más de la carga probatoria y al juez su aplicación sin mayores requisitos (desde la perspectiva de la seguridad jurídica y de la justicia, ligar hecho normal y prueba de presunciones resulta más funcional. Sobre los conceptos funcionales infra nota 14).

${ }^{32}$ A este respecto, la sentencia citada entrega dos pautas que podrían servir de fundamento a la determinación de algunos de los aludidos grupos de casos. Primero, daños morales que pueden ser inferidos a partir de ciertas lesiones a la integridad física o psíquica; y segundo, daños morales que, en cuanto son consecuencia de la afectación de cosas corporales, deben ser acreditados en el proceso mediante la aportación de pruebas directas. 
rebote, y el caso de la prueba del daño moral por incumplimiento de contrato:

Respecto del primer tipo se puede entender, que la mera relación de parentesco puede constituir indicio de daño moral respecto de parientes próximos. Nuestros tribunales suelen inferir el daño moral a partir de la sola demostración de la relación de parentesco, argumentando que "la naturaleza humana es propensa a sufrir por la pérdida de sus deudos más cercanos»"33, o que «...el daño moral consiste en el dolor, pesar o sufrimiento que significa la muerte de su hijo y las lesiones graves de su hija, lo que basta para demostrarlo, la relación familiar entre ellos, acreditado con los certificados respectivos, quedando al sentenciador su apreciación pecuniaria» (el destacado es nuestro) $)^{34}$.

La postura recién transcrita ha sido criticada por alguna doctrina, sosteniendo en su lugar, que debe acreditarse además la relación afectiva en que se fundamentaría el daño moral invocado. Compartimos dicha crítica respecto de sus aplicaciones jurisprudenciales más radicales (aquellas que no admiten prueba en contrario y que han dado lugar a indemnizaciones respecto de parientes cuya enemistad o descuido con la víctima directa han sido acreditados); sin embargo, discrepamos en la medida en que creemos, que la aplicación de las reglas de la experiencia, permite legítimamente presumir de la sola relación de parentesco una relación afectiva que justifica la existencia del respectivo daño moral. Lo anterior encontrará aplicación siempre y cuando - claro está-, no existan en el proceso antecedentes que impidan la aplicación de tales reglas de experiencia ${ }^{35}$.

${ }^{33} R D J$, T. LXIII, secc. 4. ${ }^{\text {, }}, 1966$, p. 129.

34 RDJ, T. LXV, secc. 4. ${ }^{\text {, }} 1969$, p. 21.

$35 \mathrm{Al}$ respecto, volvemos a citar jurisprudencia venezolana en la cual se expresan estas cuestiones con toda corrección, explicitación que no se encuentra presente en nuestra jurisprudencia. "Al respecto, debe decirse que si bien la jurisprudencia de esta Sala ha recurrido tradicionalmente a la elaboración de presunciones para efectos de la demostración del perjuicio moral, en relación con los parientes cercanos, es claro que aquéllas se fundan en un hecho probado, esto es, la relación de parentesco, de manera que a partir de ella - que constituye el hecho indicador, o el indicio propiamente dicho, según la definición contenida en el artículo 248 del Código de Procedimiento Civil -, y con fundamento en las reglas de la experiencia, se construye una presunción, que permite establecer un hecho distinto, esto es, la existencia de relaciones afectivas y el sufrimiento consecuente por el daño causado a un pariente, cuando éste no se encuentra probado por otros medios dentro del proceso. Y tal indicio puede resultar suficiente para la demostración del perjuicio moral sufrido, en la mayor parte de los casos; en otros, en cambio, pueden existir elementos de convicción en el expediente que impidan la aplicación llana de la correspondiente regla de la experiencia.". Sentencia citada precedentemente (nota.$^{\circ} 28$ ). Respecto a antecedentes que impidan la aplicación de una presunción en 
Respecto del segundo tipo (daño moral derivado de contrato) se puede sustentar, que por regla general el solo incumplimiento de un contrato no puede ser considerado indicio de daño moral. Teniendo por superada la discusión en torno a su aceptación en vía contractual, nuestros tribunales han comenzado a desarrollar una línea jurisprudencial que luego de afirmar su carácter excepcional, sostiene que no basta la sola demostración del incumplimiento contractual para tenerlo por acreditado. Se ha dicho así que, «..., para que exista daño moral, derivado de responsabilidad contractual, no es suficiente que se deje de cumplir el contrato... No es posible establecer que por el solo incumplimiento de un contrato se derive dolor y aflicción susceptibles de ser indemnizados por vía de daño moral..." (el destacado es nuestro) ${ }^{36}$.

Aunque hemos citado este caso simplemente con una intención ejemplificadora, efectivamente su inclusión resulta pertinente pues sirve para reiterar dos posiciones. La primera es que a efectos de la responsabilidad civil el mero incumplimiento contractual no solo no produce daño moral sino ningún tipo de daño, pues estos deben ser siempre probados; y la segunda, que debido a la naturaleza de las prestaciones comprometidas, hay algunos tipos de contratos cuyo incumplimiento podría llegar a ser considerado indiciario de daño moral (v.gr. el caso del contrato médico).

\section{El problema de los medios probatorios idóneos y el problema de la apreciación de la prueba rendida: ¿Cómo han de probarse los daños morales?}

Quizás el aspecto clave a resolver en lo que se relaciona con la prueba de los daños morales tiene que ver con la técnica o procedimiento que la misma requiere, de ahí que como tercer presupuesto de una teoría de la prueba del daño moral debe requerirse, que la misma ha de ser pertinente y útil: respecto de las partes, ellas tendrán que

estos casos, nuestros tribunales han señalado que, "El demandado civil no ha demostrado que entre la demandante y sus padres fallecidos en el accidente, existieran malas relaciones $u$ otra situación análoga que justificara la carencia de afecto entre ellos.» RDJ, T. LXXX, secc. $1 .^{\circ}, 1983$, p. 128.

${ }^{36}$ Un comentario del fallo citado puede verse en Cárdenas Villarreal, Hugo. De la extensión de la reparación del daño moral derivado de contrato. En: Revista Chilena de Derecho. Vol. 31 n. ${ }^{\circ}$ 2. Santiago: Pontificia Universidad Católica de Chile, mayo-agosto de 2004, pp. 379-387. Cfr. también, Rodríguez G., Pablo, Responsabilidad contractual, Santiago: Ed. Jurídica de Chile, 1999. pp. 252 y ss. 
presentar aquellas que correspondan; respecto del juez, éste solo deberá aceptar y otorgar valor a aquellas que tengan eficacia probatoria.

\subsection{El problema de los medios probatorios idóneos: la prueba aducida debe ser pertinente y útil ${ }^{37}$.}

La idea de que las partes deben rendir una prueba capaz de producir en el juez la convicción necesaria, para que éste dé por acreditado los hechos constitutivos del daño moral que se alega (por ello se dice pertinente y útil) resulta sencillamente incontrovertible; de allí que se hable de medios probatorios idóneos. Empero, y como ya adelantamos, a esta finalidad no sirve una delimitación demasiado amplia del objeto de la prueba (el daño moral); por lo que se hará necesario o bien restringir el concepto, o bien, introducir dentro del mismo, las distintas categorías que de manera cristalina, revelen aquellos extremos sobre los que debe recaer la prueba (el objeto de la misma).

Así las cosas, las subcategorías o tipos de daño moral, nos arrojarán los hechos constitutivos o, en su caso (piénsese en la prueba de presunciones a que aludimos más arriba), los hechos fundantes del daño moral, en relación a los cuales determinaremos los medios de prueba más idóneos, es decir, aquellos que causen más convicción en el juez. Unos ejemplos servirán para explicarnos: en caso de que utilicemos el pretium doloris como una subcategoría, el hecho constitutivo será la aflicción espiritual, pena, etc. experimentada por la víctima; y los medios de prueba más idóneos serán la prueba pericial (informes médicos), la declaración de la víctima y la declaración de testigos. En caso de que utilicemos la subcategoría del daño estético, el hecho que habrá de probarse será la alteración objetiva de la imagen física de la víctima; siendo entonces pruebas especialmente idóneas, la presentación de fotografías anteriores y posteriores al hecho dañoso, la inspección personal del tribunal y el informe pericial ${ }^{38}$.

37 Sobre este tema puede verse en el derecho español, Gesto A., Blanca. La pertinencia y utilidad de las pruebas. Pamplona: Universidad de Navarra, 1991.

${ }_{38}$ A este respecto, se ha fallado en sentido negativo que «... con relación al daño moral no puede estimarse seriamente que podría estar acreditado con el informe de fojas $\boldsymbol{x}$, que concluye que el demandante sufrió lesiones explicables por accidente de tránsito, clínicamente leves y que sanará salvo complicaciones en 10 o 12 dias con igual tiempo de incapacidad. La indemnización por daño moral debe basarse en un sufrimiento efectivo, consecuencia de un acto doloso o imprudente, como ser verse físicamente imposibilitado, disminuido o defectuoso, como secuela de tal acto" (el destacado es nuestro). $R D J$, T. LXXVIII, secc. $2 .^{\circ}, 1981$, p. 36. Por otra parte, ahora en sentido 


\subsection{El problema de la apreciación de la prueba rendida: el sistema de la persuasión racional.}

En materia civil, el juez se debe sujetar a los medios de prueba establecidos por el legislador, pero valorándolos conforme a la convicción que se forme de los hechos, debiendo en todo caso, explicitar en la sentencia las razones que justifican su valoración: los jueces se encuentran regidos así por el llamado sistema de la "persuasión racional» ${ }^{39}$. En dicho sistema, la ley regula extremos que dicen relación con la determinación de los medios probatorios, con su admisibilidad, con las causas de tachas de los testigos, y con la forma en que ha de rendirse la prueba ${ }^{40}$.

Aun considerando que la tantas veces resaltada naturaleza compleja del perjuicio moral, se traduce en una mayor dificultad probatoria, en ningún caso viene a variar la regla general en materia de valoración de la prueba («persuasión racional»), situando al juzgador dentro del sistema del "íntimo convencimiento ${ }^{41}$, lo que parece ser afirmado por quienes sostienen que la prueba del daño moral es una materia entregada a la discrecionalidad del juez. Por ello, creemos procedente el recurso de casación en la forma respecto de la determinación del daño moral ("vicio de inmotivación»), cuando el juez no expresa en forma clara y precisa los razonamientos de hecho que lo llevan a rechazar o a dar por probado el daño moral (señalamiento de pruebas admitidas y su correspondiente valoración).

positivo se ha sostenido que «la declaración del médico, la ficha clínica y demás antecedentes del tratamiento médico son contestes en cuanto al sufrimiento soportado y a la afección sicológica del autor»; por consiguiente son antecedentes pertinentes y útiles para la acreditación del respectivo daño moral. $G J$, T. 205, p. 174.

39 En este mismo sentido, PaIllas, Enrique. Estudios de derecho probatorio. Santiago: Ed. Jurídica de Chile, 2002. p. 30. En contra, la doctrina mayoritaria entiende que en nuestro sistema, la prueba legal o tasada constituye el régimen general de valoración de la prueba. Este sistema en todo caso, se reconoce se encuentra en franca retirada debido a las numerosas materias en que el legislador confiere a los tribunales la facultad de apreciar la prueba conforme a las reglas de la sana crítica. Sobre el tema véase recientemente GonZÁlez CASTILlo, Joel. La fundamentación de las sentencias y la sana crítica. En: Revista Chilena de Derecho. Vol. 33. N. ${ }^{\circ}$ 1. Santiago: Pontificia Universidad Católica de Chile, enero-abril de 2006. pp. 93-107.

${ }^{40}$ Ibid., p. 23.

${ }^{41}$ Aquel sistema de valoración de la prueba, en el cual la determinación de los hechos se encuentra entregada por entero a la conciencia del juez, el cual no está obligado por ninguna prueba legal, entendiéndose que puede escoger las fuentes de su convicción fuera de los medios legales y por otra parte, no se encuentra obligado a fundamentar sus sentencias. Paillas, E., Estudios ..., Op. Cit., p. 21. 
Antes de finalizar, y aún cuando como señalamos al introducir estas notas, la cuestión de la avaluación excede el propósito de nuestro trabajo, no queremos dejar de hacer una breve referencia a dos principios que deben ser tenidos en cuenta en esta materia. Y es que, si bien no es posible hacer una valoración exacta de dicho daño, la misma debe, en todo caso, cimentarse en los antecedentes que se encuentren en el proceso.

\subsubsection{El principio de la apreciación subjetiva de la medida de la reparación}

Al revisar la medida de la reparación cabe utilizar dos criterios. Uno de ellos será objetivo, e implicará que el valor de la indemnización se fijará de acuerdo al valor de mercado del bien lesionado; el otro subjetivo, e implicará que la reparación tendrá como objeto el valor específico que el bien tuviese para el concreto perjudicado (de su específico interés en terminología de DE CuPIS; o del daño propio, en la de YzQuiERDo) ${ }^{42}$. Dado que el daño moral es una categoría de suyo subjetiva y la finalidad de la responsabilidad civil es la reparación de la víctima, creemos, que con «ciertos límites», ha de ser el criterio subjetivo el que ayude a determinar la indemnización.

\subsubsection{El principio procesal de congruencia como límite de la reparación.}

En nuestro Derecho, al igual que en el derecho comparado, se han desarrollado una serie de pautas o criterios que el juez ha de considerar en la determinación de la correspondiente indemnización ${ }^{43}$.

42 De Cupis, A. (1975). El daño. (Ángel Marínez, Trad). Barcelona: Bosch. p. 344. YZQUIERDO TOLSADA, Mariano. Sistema de responsabilidad civil, contractual y extracontractual. Madrid: Dykinson, 2001 p. 144. Sobre el tema puede verse también, NAVIERA ZARRA, Maita, El resarcimiento del daño en la responsabilidad civil extracontractual, Madrid: Editoriales de Derecho Reunidas, 2006. pp. 197 y ss.

${ }^{43}$ Las pautas o criterios generalmente mencionados como aquellos que deben regir la reparación del daño moral, son las siguientes: a) La reparación integral del daño; b) Evitar las indemnizaciones en globo y procurar una evaluación separada y fundamentada de cada una de las partidas de la indemnización; c) Creación de tablas o baremos para daños morales que permiten al juez un parámetro para fijar la indemnización; d) Consideraciones de carácter macro y macroeconómicas, es decir, el grado de desarrollo económico del país y la situación particular de la víctima y de la persona obligada; y e) Publicaciones periódicas de las indemnizaciones judiciales, con lo cual se consigue obtener una información estadística que en cierto modo sirva para uniformar las decisiones en casos semejantes. 
Nuestros tribunales suelen enumerar algunos de tales criterios para luego simplemente señalar casi como una fórmula de estilo que, conforme al mérito de autos, se fija la correspondiente indemnización en una determinada cantidad ${ }^{44}$.

Lo dicho, además de no contribuir de manera efectiva en la valoración, no supone una justificación suficiente, y por tanto, constituye la violación de uno de los principios fundamentales de la prueba ya mencionados ${ }^{45}$. Entiéndase, que si lo buscado es reducir efectivamente la arbitrariedad, de modo tal que la determinación del monto de la indemnización sea más transparente y fundamentada, no basta el señalamiento sin más de los criterios o pautas tomados en consideración, agregando que todos ellos fueron ponderados por el tribunal para arribar a su decisión. Por tanto, como petición de principio, se ha de explicitar el modo en que se ha efectuado tal operación, partiendo por señalar el peso específico o relevancia (este es el sentido fundamental de ponderar) de cada uno de tales criterios en la determinación de la indemnización, aduciendo además las razones que se han tenido para ello.

Sin perjuicio de que se puedan introducir otros parámetros, entendemos de suma importancia la aplicación del principio de congruencia en al menos dos sentidos, y cuya infracción creemos podría justificar la anulación casacional la sentencia por defectos en la avaluación del daño moral:

a) Lo solicitado en la demanda es el límite máximo de la indemnización

Nuestra Corte Suprema ha estimado que no existe vicio de ultra petita respecto de lo fallado por el tribunal ad quo cuando se otorga una cantidad superior a la demandada ${ }^{46}$. A nuestro parecer la alta magistratura incurre en un error palmario, pues como se sabe, la justicia civil es una justicia rogada. Ciertamente, en virtud del principio

44 «Por lo dicho, sólo resulta ajustado a la prudencia y equidad, regular de manera razonable y equitativa el monto actual de la expresada indemnización compensatoria, apreciando para ello, también en forma prudencial, todos los datos legalmente concurrentes sobre el carácter y extensión del daño con arreglo al mérito probatorio aceptable que arroja el proceso, acerca del hecho mismo, sus consecuencias en la victima y las circunstancias personales de ésta, sin perjuicio - naturalmente- de establecer, además una justa compensación por el disvalor de la moneda hasta que se verifique el pago de la suma que se dirà" (el destacado es nuestro). GJ, T. 50, p. 108.

45 Ver supra., II, A, 1: El principio al debido proceso (motivación de la sentencia/derecho a defensa).

46 Diez S., J. L., El daño ..., Op. Cit., p. 272. 
de congruencia, el tribunal se encuentra constreñido por el monto solicitado por el ofendido (lo que constituye su pretensión), de manera que dicho monto se constituye en el tope máximo de la indemnización que puede ser concedida ${ }^{47}$. Aunque no podemos detenernos en ello, baste dejar sentado aquí, que entendemos, que en casos como el descrito se configuraría el aludido vicio de ultra petita, y por ende, sería procedente la impugnación de la sentencia a través del recurso de casación en la forma.

b) Ponderación de los criterios de avaluación fundamentada en antecedentes objetivos

Otra manifestación del principio de congruencia está constituida por la exigencia de que la avaluación se fundamente en antecedentes objetivos, en el sentido de que el juez no sólo debe explicitar los criterios de avaluación utilizados, sino además, debe ponderarlos a partir de los antecedentes que se encuentren presentes en el proceso y respecto de los cuales se haya rendido prueba $^{48}$. A este respecto, y aparte de la ya aludida posibilidad de anulación formal por falta de motivación, pensamos que en aquellos casos en que tales criterios se encuentran positivados ${ }^{49}$, y la avaluación realizada por el tribunal sea manifiestamente desproporcionada, sería procedente el recurso de casación en el fondo por infracción a la norma que los recoge.

\section{CONCLUSIONES}

Hoy en día podemos empezar a dar por superados, los influjos de aquella filosofía ilustrada que concebía al hombre como un sujeto racional titular de bienes de carácter material. En su evolución, el derecho civil ha ido descubriendo y construyendo el rostro de su nuevo sujeto, el rostro de la persona, del hombre de carne y hueso, que poseedor de bienes materiales y morales, sufre y padece: el código no le habla más al «corazón de los propietarios» ${ }^{50}$; el código habla ahora al

47 En este mismo sentido, en el derecho español, NAvEIRA Z., M., El resarcimiento ..., Op. Cit., pp. 215-216.

${ }_{48}$ Cfr. Domínguez H., C., El daño moral en Chile. Contornos y problemas. En Revista Anales Derecho UC. N. ${ }^{\circ}$ 1. Santiago: Legis-Pontificia Universidad Católica de Chile, agosto de 2006. p. 327. IrIBARne, H., La prueba ..., Op. Cit., pp. 96 y ss.

49 Como es el caso de la llamada Ley Auge (n. ${ }^{\circ} 19.966$ D.O. 03/09/03), en cuyo artículo 41 establece que: «La indemnización por daño moral será fijada por el juez considerando la gravedad del daño y la modificación de las condiciones de existencia del afectado con el daño producido, atendiendo su edad y condiciones físicas».

50 Grossi, PaOlo. (2003). Mitología jurídica de la modernidad. (Manuel Martínez, Trad). Madrid: Trotta. p. 83. 
corazón de las personas. Ninguna duda cabe, que fueron precisamente instituciones como el daño moral las que comandaron, y a la vez recepcionaron esa integración conceptual que sufrió el sujeto de derecho. Sin embargo, esa evolución no puede darse aún por concluida ni mucho menos, abandonarse a su suerte, pues mientras no afinemos las técnicas jurídicas que nos permitan articular con igualdad de trato, y finalmente hacer efectiva esta nueva concepción en los casos concretos, nada se habrá hecho.

Es en este contexto, en el que el desarrollo de una teoría tópica y funcional que regule satisfactoriamente la prueba del daño moral se hace impostergable. Dicha teoría, si bien no debe despreciar los aportes de nuestra jurisprudencia en la materia, debe buscar su racionalización, acomodando y dirigiendo su regulación a los principios que han de sustentarla. En términos generales, y nos remitimos aquí al cuerpo de este escrito, en la construcción de esta teoría deviene indispensable la realización de subcategorías o subtipos de daños morales. Lo recién dicho, inicialmente nos permitirá distinguir aquellos supuestos de daños morales que pueden ser acreditados mediante prueba de presunciones, de aquellos que no. Respecto de estos últimos, se podrá entonces, precisar los hechos que han de ser considerados constitutivos de los mismos para, conforme a ellos, determinar las pruebas más idóneas para lograr su acreditación.

Quede por último subrayado, que en éste como en ningún otro tema, la vinculación del precedente se constituye en condición necesaria para que la formulación de los aludidos grupos de casos presente alguna utilidad. A los fervientes defensores de una mal entendida «independencia judicial» solo resta decir, que en nuestro sistema jurídico la vinculación al precedente deviene exigencia del derecho a un justo y racional procedimiento, y de la igualdad ante la ley que a todos se nos supone: como prescribe nuestro texto constitucional, «ni la ley ni autoridad alguna podrán establecer diferencias arbitrarias».

\section{BIBLIOGRAFÍA}

Agoglia, María, Boragina, Carlos y Meza, Jorge. La prueba del daño. En Revista de Derecho de Daños. N. ${ }^{\circ}$ 4. Mendoza: Rubinzal-Culzoni, 1999. pp. 157-172.

Arazi, Roland. Prueba del daño moral. En: Revista de Derecho de Daños. N. ${ }^{\circ}$ 6. Mendoza: Rubinzal-Culzoni, de 1999. pp. 103-111.

CÁRDENAS VillarReAL, Hugo. De la extensión de la reparación del daño moral derivado de contrato. En Revista Chilena de Derecho. Vol. 31 n. ${ }^{\circ}$ 2. San- 
tiago: Pontificia Universidad Católica de Chile, mayo-agosto de 2004, pp. 379-387.

- Daño moral: algunas notas para su delimitación, comentario de jurisprudencia. En Jurisprudencia al Día. Año 5, n. ${ }^{\circ} 285$, Santiago: Ed. Lexis Nexis, abril de 2006, pp. 42-45.

Cárdenas V., Hugo y González Vergara, Paulina. Notas sobre el daño moral: concepto, prueba y avaluación en una reciente sentencia de la Corte de Apelaciones de Santiago, nota a fallo. En Revista de Derecho. Año 12, n. ${ }^{\circ}$ 2. Coquimbo: Universidad Católica del Norte, julio-diciembre de 2005. pp. 181-189.

CORRAL TALCIANI, Hernán. Lecciones de responsabilidad civil extracontractual. Santiago: Ed. Jurídica de Chile, 2004.

De CuPIS, A. (1975). El daño. (Ángel Marínez, Trad). Barcelona: Bosch.

Diez-Picazo, Luis. Derecho de daños. Madrid: Civitas, 1999.

DíEz SCHWERTER, José Luis. El daño extracontractual. Jurisprudencia y doctrina. Santiago: Ed. Jurídica de Chile, 2002.

Domínguez Hidalgo, Carmen. Aspectos modernos de la reparación por daño moral. Contraste entre el derecho chileno y el derecho comparado, En: Revista de Derecho. Año 6. Coquimbo: Universidad Católica del Norte. 1999. pp. 29-46.

Domínguez Hidalgo, Carmen. El daño moral t. 1 y 2. Santiago: Ed. Jurídica de Chile, 2002.

- El daño moral en Chile. Contornos y problemas. En Revista Anales Derecho UC. N. ${ }^{\circ}$ 1. Santiago: Legis-Pontificia Universidad Católica de Chile, agosto de 2006. pp. 307-328.

Fueyo LANERI, Fernando. Instituciones de Derecho Civil Moderno. La resarcibilidad del daño moral como tutela de los bienes y derechos de la personalidad. Santiago: Ed. Jurídica de Chile, 1990.

Gesto A., Blanca. La pertinencia y utilidad de las pruebas. Pamplona: Universidad de Navarra, 1991.

GonZÁLEZ CASTILLO, Joel. La fundamentación de las sentencias y la sana crítica. En: Revista Chilena de Derecho. Vol. 33. N. ${ }^{\circ}$. Santiago: Pontificia Universidad Católica de Chile, enero-abril de 2006. pp. 93-107.

GozAINI, Osvaldo Alfredo. El debido proceso en la actualidad. En I Congreso Panameño de Derecho Procesal. Ciudad de Panamá, agosto de 2004. pp. 351-366.

Grossi, PaOlo. (2003). Mitología jurídica de la modernidad. (Manuel Martínez, Trad). Madrid: Trotta.

Hoyos, Arturo. El debido proceso en el sistema jurídico de Panamá. En I Congreso Panameño de Derecho Procesal. Ciudad de Panamá, agosto de 2004. pp. 307-328.

IRIBARNE, Héctor. La prueba en el juicio de daños a la persona. En: Revista de Derecho de Daños. N. ${ }^{\circ} 4$. Mendoza: Rubinzal-Culzoni, 1999. pp. 63-100.

LARENZ, Kart. (2001). Metodología de la ciencia del derecho. (Marcelino Rodríguez Molinero, Trad.). Barcelona: Ariel Derecho.

LunA SERRANo, Agustín, Las ficciones legales y algunas figuras afines. En Caminos Romanos (Viae Romanae), Estudios en homenaje a Francisco 
Samper Polo, Juan David Terrazas ed., Santiago: Universidad Andrés Bello, 2006. pp. 215-223.

Mora MORA, Luis Paulino, Las garantías del procesado como parte del debido proceso. En I Congreso Panameño de Derecho Procesal. Ciudad de Panamá, agosto de 2004. pp. 329-349.

MOSSET ITURRASPE, Jorge y NovELLINO, Norberto, La prueba en el proceso de daños, En: AA. vv., Derecho de Daños, tercera parte. Buenos Aires: Ed. La Rocca, 2000.

NAVIERA ZARRA, Maita, El resarcimiento del daño en la responsabilidad civil extracontractual, Madrid: Editoriales de Derecho Reunidas, 2006.

PaIllas, Enrique. Estudios de derecho probatorio. Santiago: Ed. Jurídica de Chile, 2002.

RodRíGuez G., Pablo, Responsabilidad contractual, Santiago: Ed. Jurídica de Chile, 1999.

Stoco, Rui, Tratado de responsabilidade civil, 6. ${ }^{\mathrm{a}}$ ed. Sao Pablo: Ed. Revista Dos Tribunais, 2004.

VICARI, Alejandro y UgARTE, Eduardo, Edición del curso de responsabilidad civil extracontractual del profesor Enrique Barros Burie, Santiago, 1999, Tesis de Licenciatura (Licenciado en Ciencias Jurídicas y Sociales). Universidad de Chile. Facultad de Derecho. Departamento de Derecho Privado.

YZQUIERDo TOLSADA, Mariano. Sistema de responsabilidad civil, contractual y extracontractual. Madrid: Dykinson, 2001. 